\title{
PELATIHAN PENGELASAN APLIKATIF BAGI SANTRI PONDOK PESANTREN TAHFIDZUL QUR'AN “DARUL ULUM” MAGETAN
}

\author{
Fredy Susanto*, Alfi Tranggono Agus Salim, Indarto Yuwono, Wahyu Pribadi, Sulfan \\ Bagus Setyawan, Khairul Anam Basyar, Jovial Auliya Furqan, \\ Muhammad Abdul Aziz, Ubaeydilah ma'ruf \\ Politeknik Negeri Madiun \\ Jl. Serayu No.84, Pandean, Taman, Kota Madiun, Jawa Timur 63133 \\ email: : fredy@pnm.ac.id
}

\begin{abstract}
Welding technology is applied technology. Welding technology (method) is applied to products made of metal by requiring connections that exceed the strength of the material (metal). The application of welding technology in education and society. In the field of education carried out in vocational schools or formal vocational colleges while in the community carried out in the form of training. The welding training in the community is carried out with a community service program, which is an applicative welding training service for Islamic boarding school students. Religious education in Islamic boarding schools leads to the formation of affective and attitudes so that it is relatively lacking in the field of skills, therefore welding training is carried out for Islamic Boarding School students to add skills in the field of welding. This training applies welding technology (methods) to produce products. The training stage starts from the introduction, welding techniques to welding applications to make products. The resulting product is a folding table used for Islamic boarding school students. This training has a positive impact on Islamic boarding school students who follow the training to master the welding skills and skills possessed the opportunity to be developed in the field of entrepreneurship.
\end{abstract}

Keywords: skills, community service, welding, applicative, Islamic boarding school, PKM

\begin{abstract}
Abstrak
Teknologi pengelasan merupakan teknologi terapan. Teknologi pengelasan (metode) diaplikasikan pada produk berbahan logam dengan membutuhkan penyambungan yang melebihi kekuatan material (logam). Penerapan teknologi pengelasan dilakukan didunia pendidikan maupun masyarakat. Pada dunia pendidikan dilakukan dipendidikan formal sedangkan dimasyarakat dilakukan dalam bentuk pelatihan. Pelatihan pengelasan dimasyarakat dilakukan dengan program pengabdian masyarakat yaitu pengabdian pelatihan pengelasan aplikatif bagi santri pondok pesantren. Pendidikan keagamaan di pondok pesantren mengarah ke pembentukan afektif dan sikap sehingga relatif kurang dibidang keterampilan, oleh karena itu dilaksanakan pelatihan pengelasan bagi santri Pondok Pesantren untuk menambahkan keterampilan dibidang pengelasan. Pelatihan ini menerapkan teknologi pengelasan (metode) hingga menghasilkan produk. Tahapan pelatihan diawali dari pengenalan, teknik pengelasan hingga aplikasi pengelasan untuk membuat produk. Produk yang dihasilkan berupa meja lipat yang digunakan untuk santri Pondok Pesantren. Pelatihan ini memberikan dampak positif bagi santri pondok pesantren yang mengikuti pelatihan hingga menguasai keterampilan pengelasan dan ketrampilan yang dimiliki memiliki kesempatan untuk dikembangkan dibidang kewirausahaan.
\end{abstract}

Kata Kunci: keterampilan, pengabdian masyarakat, pengelasan, aplikatif, pondok pesantren, PKM

\section{PENDAHULUAN}

Pondok pesantren merupakan sentral pendidikan luhur yang merupakan sebuah lembaga bergerak di bidang pendidikan dengan dasar agama sebagai kurikulum utama. Berdirinya Pondok Pesantren "Darul Ulum" yang berlokasi di desa 
Mangu Kecamatan Takeran Kabupaten Magetan Jawa Timur dilatarbelakangi oleh masalah berkurangnya kesadaran para calon generasi muslim untuk mempelajari dan memahami Al Quran, khususnya dibidang tahfidzul Qur'an (menghafal Al Qur'an).

Pendidikan agama disebuah pesantren mengarah ke pembentukan afektif dan sikap, namun jika hanya mengarah ke pendidikan sikap saja pesantren memiliki kekurangan, yaitu lulusan pondok pesantren yang kurang terampil. Melihat kondisi seperti diatas maka salah satu langkah yang perlu diambil adalah dengan pemberdayaan santri pondok pesantren dengan mengikuti diklat ketrampilan. Peningkatan kualitas SDM yang dimulai sejak dini dapat berpengaruh pada daya saing individu itu sendiri untuk mempersiapkan dalam bersaing didunia kerja.

\section{Permasalahan Mitra}

Tingkat kemauan berwirausaha yang harus dimiliki masyarakat Indonesia yang masih rendah, karena pendidikan pesantren yang masih bersifat keagamaan dan pendidikan sikap saja. Oleh karena itu diadakannya pelatihan keterampilan yang dikemudian hari dapat dikembangkan untuk berwirausaha.

Dengan penguasaan keterampilan pengelasan maka masyarakat alumni pondok pesantren juga memiliki ketrampilan berwirausaha dan akan mampu bersaing di era globalisasi. Oleh karena itu, diperlukan kepedulian kalangan akademisi untuk turut serta membantu dalam peningkatan kualitas SDM masyarakat tersebut melalui pelatihan pengelasan. Hasil yang diharapkan dari lulusan pondok pesantren selain memiliki jiwa yang bertaqwa juga memiliki keterampialn dibidang pengelasan yang berpontensi dikembangkan untuk berwirausaha

\section{METODE PENGABDIAN}

\section{A. Metode Pelaksanaan Pelatihan}

Metode yang digunakan dalam pengabdian masyarakat pengelasan dasar adalah

1. Teori

Pelatihan pengelasan dasar dilaksanakan dalam kelas sehingga memudahkan peserta untuk memahami proses pembelajaran [1].

2. Praktek

Proses pelatihan pengelasan aplikatif perlu ditunjang maka dibutuhkan sebuah kegiatan pengalaman langsung yaitu berupa praktek pemotongan, penyambungan dan pembersihan hasil las. Dengan metode praktik maka peserta mampu melakukan simulasi dan menerapkan apa yang telah dipelajari dalam teori sehingga dapat menghasilkan produk pengelasan [1].

\section{B. Prosedur Pelaksanaan}

Pelaksanaan pengabdian masyarakat ini dilaksanakan dalam kurun waktu 3 bulan yaitu mulai bulan Mei 2019 hingga Juli 2019 dengan prosedur kerja pada gambar 2.1, dari tahapan persiapan tim panitia, pembuatan materi pelatihan, teknik pelaksanaan hingga kegiatan pelatihan. Pelatihan dilaksanakan di Lab. Manufaktur Prodi D IV Perkeretaapian, Politeknik Negeri Madiun. Aktif kegiatan dilaksanakan selama 2 hari. 


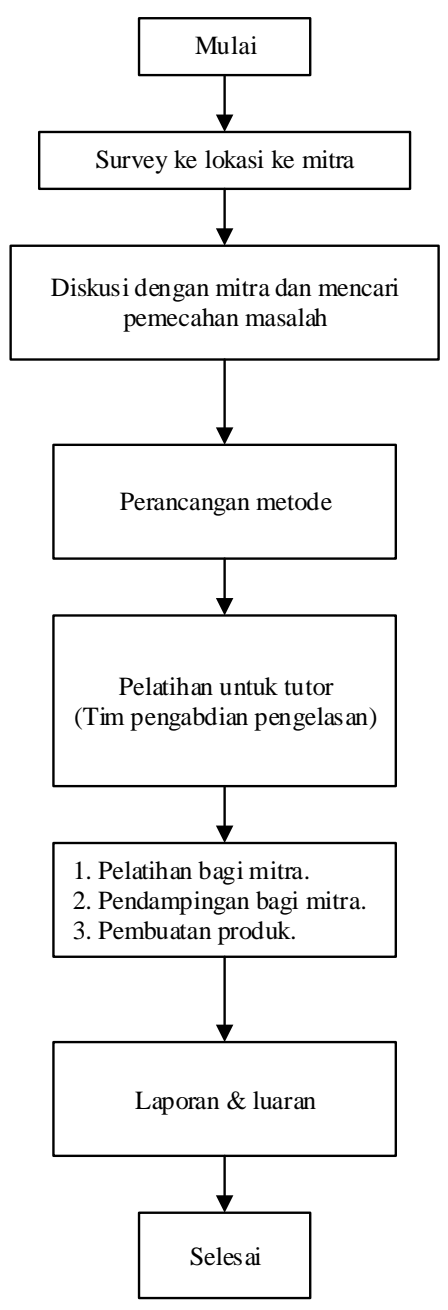

Gambar 2.1 Prosedur kerja pelaksanaan program

\section{Pelatihan Kepada Mitra}

Program ini terlaksana melalui bentuk kerjasama dengan santri Pondok Pesantren Darul Ulum berdasarkan target luaran yang ingin dicapai. Pelaksanaan program pelatihan ini dikelompokkan menjadi:

1. Posisi pengelasan di bawah tangan (1F dan 1G)

Pengelasan di bawah tangan adalah proses pengelasan yang dilakukan di bawah tangan dan benda kerja terletak diatas bidang datar. Sudut ujung pembakar (brander) terletak diantara $60^{\circ}$ dan kawat pengisi (filler rod) dimiringkan dengan sudut antara $30^{\circ}-40^{\circ}$ dengan benda kerja. Kedudukan ujung pembakar kesudut sambungan dengan jarak 2-3 mm agar terjadi panas maksimal pada sambungan. Pada sambungan sudut luar, nyala diarahkan ketengah sambungan dan gerakannya adalah lurus.

2. Posisi pengelasan mendatar / horizontal (2F dan 2G)

Pada posisi ini benda kerja berdiri tegak sedangkan pengelasan dilakukan dengan arah mendatar sehingga cairan las cenderung mengalir ke bawah, untuk itu ayunan brander sebaiknya sekecil mungkin. Kedudukan brander terhadap benda kerja menyudut $70^{\circ}$ dan miring kirakira $10^{\circ}$ di bawah garis mendatar, sedangkan kawat pengisi diiringkan pada sudut $10^{\circ}$ di atas garis mendatar.

$[2,3,4,5]$.

\section{Project Pembuatan Meja Lipat dari Hasil Pengelasan}

Partisipasi mitra ini diikuti dari awal kegiatan pelatihan, yaitu mitra aktif dari pertemuan awal antara mitra dengan tim program PKM dalam rangka studi lapangan untuk mendapatkan informasiinformasi yang menjadi permasalahan di Pondok Pesantren Tahfidzul Qur'an "Darul Ulum" Takeran Magetan.

Permasalahan yang ada adalah banyaknya santri yang belum mempunyai hardskill dalam hal pengelasan. Setelah lulus dari pesantren santri belum dapat untuk mandiri mencari pekerjaan, maka dengan adanya pelatihan pengelasan dasar $1 \mathrm{G}$ dalam rangka pengembangan kewirausahaan bengkel peserta akan dibekali kemampuan untuk memotong logam, melakukan pengukuran, melakukan penyambungan logam. Kemampuan ini akan berguna jika sudah lulus dari pesantren. Partisipasi pesantren dalam program pengabdian masyarakat ini adalah menyediakan ruangan kelas sebagai bengkel sementara, menyediakan peserta didik untuk dilatih sebagai operator las. Menyediakan 
tempat khusus apabila program pelatihan sudah dilaksanakan sebagai bibit pengembangan bengkel pengelasan.

\section{HASIL DAN PEMBAHASAN}

Pelaksanaan pelatihan pengelasan tidak dilaksanakan di pondok karena terkait daya listrik yang tidak cukup untuk memenuhi kebutuhan pengelasan, maka dialihkan pelatihan di Laboratorium Manufaktur Prodi DIV Perkeretaapian Politeknik Negeri Madiun, di J1. Serayu no. 84 Kota Madiun. Kegiatan pelaksanaan pelatihan ini meliputi instalasi komponen mesin las, pengecekkan kondisi mesin las, ujicoba alat oleh tim. Berikut ini tahapanyang dilaksanakan disertai dengan dokumentasi setiap sesi. Persiapan dilakukan dengan pengecekkan absensi oleh panitia, ditunjukkan pada gambar 3.1 berikut

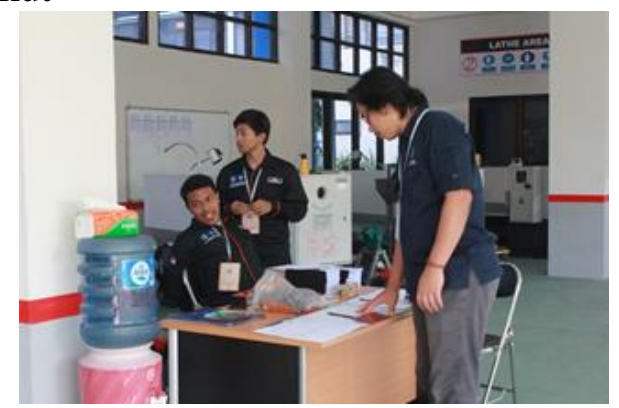

Gambar 3.1 pengecekan absensi oleh panitia

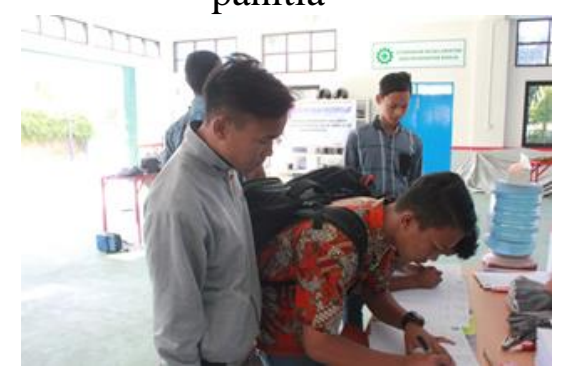

Gambar 3.2 peserta mengisi daftar hadir

Kegiatan selanjutnya pemaparan materi oleh tim pengelasan aplikatif berupa teori pengelasan $2 \mathrm{~F}, 3 \mathrm{~F}, 2 \mathrm{G}, 3 \mathrm{G}$ dan teori pembuatan meja lipat. Kegiatan pemaparan teori ditunjukkan pada gambar 3.3 berikut ini.

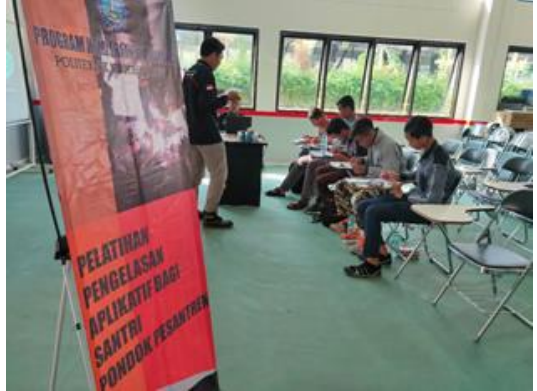

Gambar 3.3 pemaparan teori

Sebelum praktek peserta diberi tes berupa soal sejauh mana peserta bisa memahami teori pengelasan. Setelah mengerjakan soal kita koreksi bersama dan ini hasil tes dari peserta ditunjukan gambar 3.4 berikut ini

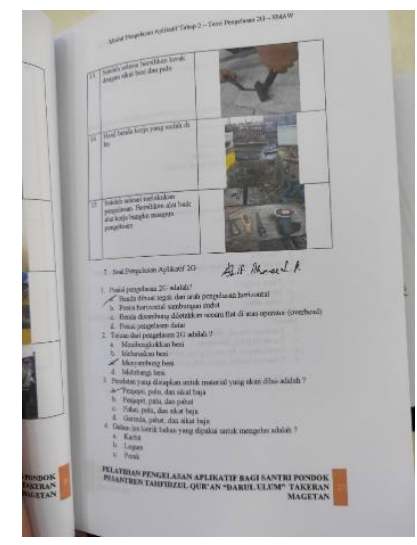

Gambar 3.4 hasil pekerjaan dari peserta

Kegiatan selanjutnya adalah peserta pelatihan diberikan kesempatan praktek mengelas dimana sebelumnya diberikan contoh cara penyalaan busur listrik. Praktek peserta didampingi oleh asisten dari tim agar tidak terjadi kecelakaan kerja. Mesin las berjumlah 4 dimana setiap kelompok didampingi 1 asisten dengan peserta 4 orang tiap sesi, ditunjukkan gambar 3.5 berikut ini.

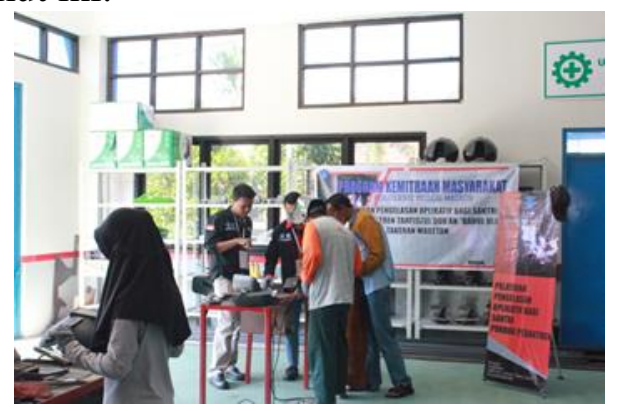

Gambar 3.5 praktek pengelasan

Tahapan praktek akhir adalah pembuatan produk dari proses pengelasan logam. Produk jadi pengelasan yang dibuat adalah meja belajar lipat. Produk meja 
belajar lipat ini diberikan oleh tim kepada pihak mitra yakni pondok pesantren "Darul Ulum" melalui perwakilan yang ditunjuk. Proses pembuatan produk jadi tangga lipat ditunjukkan pada gambar 3.6 berikut ini

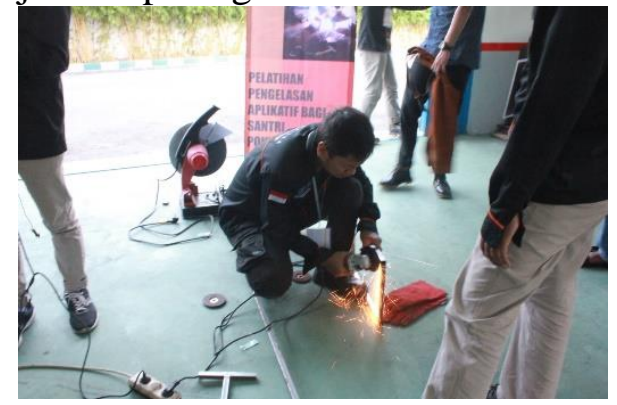

Gambar 3.6 pembuatan meja belajar lipat

Hasil pengelasan pembuatan produk meja belajar lipat yang dibuat oleh peserta. Ditunjukan pada gambar 3.7 berikut ini

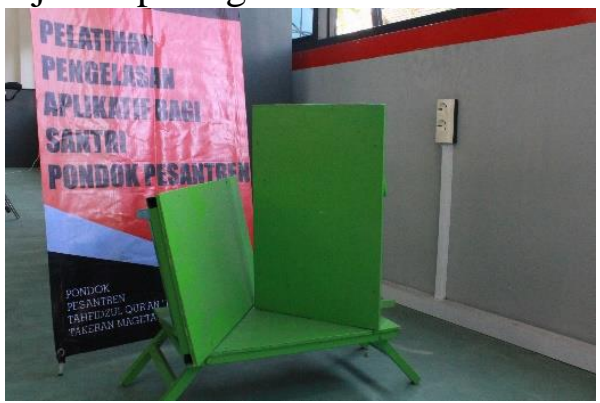

Gambar 3.7 meja belajar lipat

Foto Panitia dan Mitra saat pembukaan kegiatan PKM pelatihan pengelasan. Ditunjukan pada gambar 3.8 berikut ini

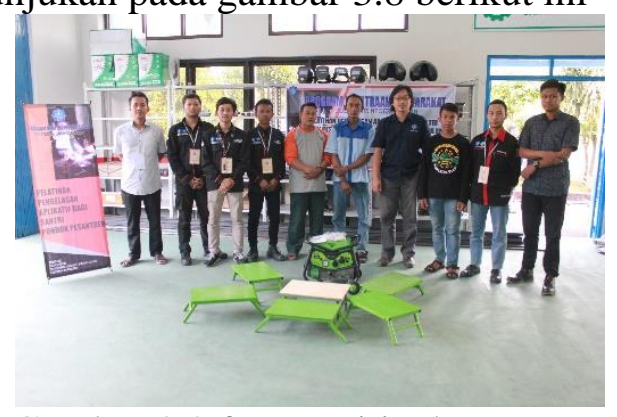

Gambar 3.8 foto panitia dan peserta

\section{SIMPULAN}

Adapun kesimpulan dari PKM berjudul "Pelatihan Pengelasan Aplikatif Bagi Santri Pondok Pesantren Tahfidzul Qur'an 'Darul Ulum" Takeran Magetan" dituliskan sebagai berikut.

1. Hasil dari survei lokasi mitra, beberapa permasalahan terkait kebutuhan pengetahuan pengelasan dalam bentuk pelatihan pengelasan.
2. Perencanaan metode dilakukan untuk menyesuaikan kebutuhan peserta, sehingga tidak membuat peserta terlalu berat dengan metode yang terlalu kompleks, karena hal terpenting peserta butuh pelatihan untuk menambah keterampilan terkait pengelasan.

3. Pelatihan tutor dilakukan dengan cara menyamakan persepsi terkait materi pengelasan yang telah disusun pada modul pelatihan.

4. Pelatihan, pendampingan dan pembuatan produk hasil pengelasan pada mitra dilakukan secara bertahap (teori hingga praktek) dan metodenya telah disesuaikan dengan kebutuhan mitra (peserta-santri).

5. Kemampuan pengelasan dasar las ini mendukung para peserta/siswa/santri untuk bisa mengembangkan dan memiliki dasar pada bidang pengelasan dan tidak menutup kemungkinan hingga kejenjang kewirausahaan

\section{UCAPAN TERIMA KASIH}

Ucapan Terimakasih kepadan Tim Pengabdian Dosen dan Mahasiswa yang telah membatu hingga terealisasi Program Kemitraan Masyarakat (PKM) yang berjudul Pelatihan Pengelasan Aplikatif bagi Santri Pondok Pesantren Tahfidzul Qur'an "Darul Ulum" Takeran Magetan. Dan ucapan terimakasih pada Politeknik Negeri Madiun, secara khusus P3M terkait dana hibah DIPA Nomor: SP DIPA042.01.2.400873/2019 Politeknik Negeri Madiun.

\section{DAFTAR PUSTAKA}

[1] Alfi Tranggono. 2017. Workshop I (Kerja Bangku dan Pengelasan). Madiun: Prodi Mesin Otomotif Politeknik Negeri Madiun

[2] http://digilib.polban.ac.id/files/disk1/7 5/jbptppolban-gdl-erwinsyahh-37423-bab2--5.pdf 
[3] http://repository.umy.ac.id/bitstream/h andle/123456789/8433/f.\%20BAB\%2 0II.pdf?sequence $=6 \&$ is Allowed $=\mathrm{y}$

[4] Metals Handbook (1989) Machining, Vol. 16, 9th Edition, ASM International, Materials Park, $\mathrm{OH}$.

[5] Sukirno. 2007. Pengembangan Modul las Listrik pada Mata Kuliah Praktik Pengelasan. Surabaya: JPTM FT Unesa 